\title{
LA OPOSICIÓN CATÓLICA AL FRANQUISMO EN VALLADOLID: LA HOAC (1960-1975)
}

\author{
POR
}

\author{
ENRIQUE BERZAL DE LA ROSA \\ Universidad de Valladolid
}

\begin{abstract}
RESUMEN
Los movimientos del catolicismo obrero en Castilla no fueron bien aceptados por los políticos franquistas, siendo especialmente vigilados desde la década de 1960 , época en la que comienzan a realizarse los primeros movimientos sociales contra el régimen.
\end{abstract}

\section{Abstract}

The movements of the worker catholicism in Castilla were not well accepted by the politicians franquistas, being especially watched from the decade of 1960 s. Then the first social movements against the Régime started to be accomplished .

\section{INTRODUCCIÓN}

a) El desmantelamiento del movimiento obrero y del sindicalismo católico bajo el franquismo. Los Movimientos Especializados de AC

La Guerra Civil en el territorio castellano supuso, como en la inmensa mayoría del país, la desarticulación del movimiento obrero organizado. Los sindicatos de clase que fueron importantes en Valladolid -en especial la UGT- fueron desmantelados muy pronto, tan pronto como triunfó la sublevación antirrepublicana del 18 de julio de 1936. También los sindicatos católicos sufrieron, a 
raíz de la unificación, la desaparición forzada en beneficio del verticalismo instaurado con la nueva organización sindical española. El sindicalismo católico castellano, y en especial el vallisoletano, importante en el terreno rural desde antes de la creación de la CONCA y presente en el ámbito urbano a través de la Casa Social Católica, se veía obligado a desaparecer. La jerarquía católica y determinados órganos de opinión no ocultaban su malestar a este respecto. En su lugar quedaba una organización que se autodenominaba católica, excusa esgrimida por las autoridades para desmantelar el resto de las organizaciones sindicales, de la Iglesia o extrafias a ella. Los Asesores religiosos de sindicatos se asegurarían de mantener la ortodoxia religiosa en el nuevo organigrama corporativo, mientras la Acción Católica se iba configurando como la plataforma asociativa desde donde experimentar nuevos cauces de participación social. Es cierto que la JOC pudo mantenerse en Valladolid, una JOC que provenía de los tiempos republicanos y que no quedó exenta de las presiones falangistas durante los primeros años de la contienda. Pero las negociaciones de Julio Martín con Onésimo Redondo, persona profundamente allegada al movimiento jocista de su ciudad natal, permitieron que la organización siguiese con vida.

La irrupción de la conflictividad obrera en Castilla y León en los años setenta encontrará en los movimientos especializados de AC, en especial en JOC y HOAC, unas plataformas privilegiadas para la organización del nuevo movimiento obrero. Y no sólo en virtud de lo que Guy Hermet, al referirse a la función política de estas asociaciones eclesiales, denominó en su función de suplencia ${ }^{1}$, sino también gracias a la aportación de militantes y de instrumentos formativos y organizativos, en gran parte novedosos y bastante efectivos ${ }^{2}$. En este sentido, los movimientos especializados de la AC obrera se convertirán en instrumentos esenciales para que trabajadores de diferentes ideologías reivindiquen sus derechos e intereses laborales. Pero también serán la cantera de nuevos militantes, encarnados en la clase obrera y fuertemente comprometidos en su promoción, protagonistas, a su vez, de la aparición de fórmulas asamblearias como exponente decisivo en los conflictos planteados por el nuevo movimiento obrero.

\footnotetext{
' G. HERMET, Los católicos en la España franquista, Ed. CIS, Madrid, 1985-1986, 2 vols.

${ }^{2}$ No nos vamos a referir a toda la bibliografia existente sobre los Movimientos Especializados de AC. Aunque es abundante, aún quedan muchísimas parcelas por investigar. Para la HOAC contamos con obras como la de B. Lopez GARCí, Introducción a la Historia de la HOAC, Ed. HOAC, Madrid, 1995; y de la misma autora, «Discrepancias y enfrentamientos entre el Estado franquista y las asociaciones obreras católicas«, en Anales de Historia Contemporánea, 5, 1986, pp. 177-189, y «Dilemas constantes en el desarrollo histórico de la HOACm, en $X X$ Siglos, 16, 1993, pp. 15-26. La revista $X X$ Siglos dedicó su número de 1993 a la ACO, y E. FERRANDo PUIG presenta un excelente y pormenorizado análisis de la organización en Contribución a la historia de la HOAC general y de Cataluña bajo el franquismo, 1946-1975, Publicaciones de la Universidat de Barcelona, 1995 (ejemplar microfilmado).
}

Actas del I Congreso de Historia de la Iglesia y el Mundo Hispánico

Hispania Sacra, 52 (2000) 


\section{b) La escasa conflictividad obrera en Castilla y León}

Castilla y León es una zona tranquila en lo que a conflictividad laboral ${ }^{3}$ se refiere. En efecto, si atendemos a los informes de las autoridades civiles y sindicales, son contadas las ocasiones en las que el orden público se ve perturbado por motivos laborales. En este sentido, se han seffalado diversas causas que explicarían este hecho: el atraso económico y el predominio rural de la zona, la mentalidad abrumadoramente conservadora de la población castellana, la fuerza de las estructuras y vivencias religiosas, y la fuerte represión desatada sobre las organizaciones sindicales de clase, sobre las ideologías y personalidades comprometidas con el régimen republicano.

Hasta finales de los afios sesenta el panorama es, salvo algún caso aislado, tranquilo, pacífico y admirado por las autoridades. Sin embargo, la década de los setenta verá alumbrar el resurgir del movimiento obrero y la conflictividad política y laboral en determinadas provincias castellanas. En efecto, si Valladolid va en cabeza de este fenómeno, tampoco Burgos, Palencia o León se ven exentas del mismo. El desarrollo industrial, las transformaciones económicas, mentales y sociales, la politización de las demandas laborales y estudiantiles, el relevo generacional en la clase obrera y estudiantil, el mayor aprovechamiento y desarrollo de los instrumentos legales representativos y participativos en el seno del sindicalismo español (Jurados, enlaces, Ley de Convenios, Consejos Provinciales de Trabajadores y Empresarios), y la aparición de nuevas y combativas plataformas asociativas, tanto sindicales como políticas, en el conjunto del país, explicarian este fenómeno. Por lo que se refiere a Valladolid, RENFE, FASA y Construcción lideran el movimiento: La revisión del Convenio será el principal desencadenante en los dos últimos casos ${ }^{4}$.

Junto a trabajadores de variada procedencia ideológica, los militantes católicos de HOAC y JOC serán protagonistas indiscutibles en el resurgir del nuevo

\footnotetext{
${ }^{3}$ F. CarantoNa Álvarez y J. C. DEL Pozo, «Comisiones Obreras en Castilla y León: de la huelga minera de 1962 al primer Congreso Regional», en D. Ruzz (dir.), Historia de Comisiones Obreras, Ed. Siglo XXI, Madrid, 1993, pp, 345-361. En otro lugar, se nos dice: «En las provincias que actualmente configuran la Comunidad Autónoma de Castilla y León, el movimiento sindical (...) tuvo una presencia no excesivamente fuerte (...). La debilidad del movimiento sindical afectó a la capacidad de la oposición democrática para articular en estas provincias un frente rupturista de relieve y posibilitó a las élites políticas del antiguo régimen una mayor capacidad de movimientos para dirigir el proceso de la Transi-

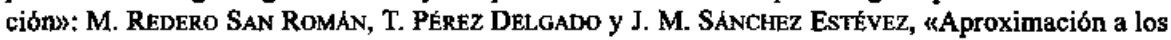
fondos documentales de los procesos de transición política y regionalización en Castilla y León», en Espacio, Tiempo y Forma, Serie V (Historia Contemporánea), n. ${ }^{\circ} 7,1994$, p. 555.

4 No vamos a detallar el origen, desarrollo y desenlace de los conflictos. Solamente nos interesa la participación de los militantes hoacistas en ellos. Para lo primero, ver el artículo citado de F. Carantofia y J. C. del Pozo.
} 
movimiento obrero en Valladolid. Gracias a ellos se pudo difundir una conciencia militante, luchadora y combativa en pro de los derechos humanos y democráticos, de la promoción de los más débiles en general y de la clase obrera en particular. Miembros de la ACO especializada pusieron en marcha las asambleas de trabajadores y encabezaron los conflictos laborales de FASA, RENFE, Construcción y otras empresas pequeñas de la ciudad. Y con la cobertura de clérigos comprometidos con el movimiento obrero pudieron poner en marcha USO, Comisiones Obreras y el movimiento asambleario y vecinal. De esta forma, muchos militantes que luego pasaron a engrosar las filas de los sindicatos CC.OO. y UGT, y de otros partidos políticos, se formaron o se lanzaron a la lucha obrera cobijados bien por estas organizaciones bien por las parroquias obreras de la ciudad.

A este respecto, los informes confidenciales de las autoridades políticas y sindicales mostraban su preocupación por la fuerza opositora que habían adquirido estos movimientos apostólicos: En los años sesenta eran los únicos que perturbaban la aparente tranquilidad de la ciudad, y a finales del primer lustro de los setenta, de nuevo ellos, junto al Partido Comunista, eran los que más amenazaban el orden público y la «paz» laboral. Como es bien sabido, a mediados de los años sesenta, la crisis de la Acción Católica fue determinante para el devenir histórico de la HOAC y demás movimientos especializados: como organizaciones, perderán buena parte de su anterior esplendor, tanto dentro de la Iglesia como en la oposición al Régimen, aunque también es cierto que seguirá vivo un importante rescoldo formativo y de actuación social. Gracias a ello, Valladolid se convirtió, desde 1970-1972, en uno de los núcleos conflictivos más importantes del país.

\section{Conflictos y Plataformas organizativas en Castilla y León}

Las primeras movilizaciones obreras no surgen en la región castellana hasta $1962^{5}$. En esta mítica fecha para la minería española, León participará en los conflictos con 5.000 obreros, según M. Tuñón de Lara ${ }^{6}$. Mucho más leves son los sucesos que acontecen en las minas palentinas de Barruelo, en RENFE, Banca y SAVA de Valladolid. El auge del movimiento obrero en la región tiene lugar en los años setenta: si en 1968 se movilizaban de nuevo los mineros leoneses, a principios de los setenta se diversifican los conflictos: las industrias

\footnotetext{
${ }^{5}$ F. Carantoña Álvarez y J. C. Del Pozo, cap. cit., pp. 146 y ss.

- España bajo la dictadura franquista, en Historia de España, Ed. Labor, Barcelona, 1981, vol. X, p. 342 .
}

Actas del I Congreso de Historia de la Iglesia y el Mundo Hispánico

Hispania Sacra, 52 (2000) 
Revilla en Soria, la construcción palentina, la industria química en Miranda de Ebro, Firestone en la ciudad de Burgos... Pero Valladolid destacará por encima de todas las demás regiones. En efecto, las huelgas de FASA, RENFE y Construcción, unidas a la movilización estudiantil y a la proliferación de plataformas asamblearias y organizativas, alterarán el tan anhelado y admirado orden público del que hacían gala hasta entonces las autoridades civiles y sindicales de la ciudad.

Como han sefialado numerosos investigadores de la historia del movimiento obrero durante el Franquismo, en los anos setenta, nuevos sectores y nuevas zonas geográficas se incorporaban a las movilizaciones obreras y al auge de los movimientos de oposición. El relevo generacional en la clase trabajadora, la labor de los movimientos apostólicos, de los curas obreros, de CCOO y demás plataformas estudiantiles, políticas y sindicales antifranquistas, y la difusión, cada vez más acentuada, de una mentalidad democrática, son factores que facilitan este fenómeno.

También es tardía la aparición de plataformas clandestinas en el terreno sindical en Castilla y León ${ }^{7}$. Por lo que se refiere a CC.OO., en Ponferrada y León surgen las primeras comisiones a principios de los sesenta -zonas mineras y RENFE-, estableciéndose formalmente a finales de la década y principios de los años setenta. En Burgos surgen en 1966, obra de hoacistas y comunistas, en Valladolid dos años más tarde, y en el resto de las provincias habrá que esperar hasta 1974-1975. También Valladolid es la primera en acoger la creación de la denominada Unión Sindical Obrera (USO) -principios de los sesenta-, y aunque en la década posterior experimentará el fuerte empuje del movimiento asambleario, serán CC.OO. las que, finalmente, logren mantener una mayor estabilidad organizativa. Como luego veremos, en Valladolid, tanto USO como CC.OO., surgirán a partir de militantes de los movimientos apostólicos -HOAC y JOC prioritariamente-, militantes que se servirán de la «protección» dispensada por determinados clérigos y destacadas parroquias «obreras».

\section{ORIGEN Y TRAYECTORIA DE LA HOAC VALLISOLETANA}

En Valladolid todo parecia favorecer la creación de asociaciones de apostolado obrero en el seno de la $\mathrm{AC}$ adulta. Aunque los sindicatos católicos fueron desmantelados, persistía la JOC de los anos anteriores a la Guerra Civil y los Hombres de AC alcanzarán un auge inusitado en los años 40 y 50. En RENFE

\footnotetext{
Ibidem.
} 
se había constituido también la Hermandad Ferroviaria de la Sagrada Familia, y serán estos talleres el núcleo originario de la HOAC vallisoletana.

Como es bien sabido, las normas de especialización obrera de 1946 supusieron la puesta en práctica de la HOAC a nivel nacional. Las recomendaciones del Pío XII a Pla y Deniel sobre el futuro político español y el modelo de las ACLI italianas serán los factores que explican tal iniciativa ${ }^{8}$. Por su parte, Valladolid acoge pronto los deseos de impulsar el apostolado entre los obreros adultos. Al igual que en el resto del país, se trataba de la clase social más alejada de la Iglesia y la que más desconfianza despertaba entre los católicos de la ciudad, sin duda por el pasado revolucionario que albergaba, muy destacado en los talleres de RENFE. Urgía, pues, lanzarse a la conquista católica de los obreros y completar así la recristianización social, favorecida y potenciada, en estos afios de la posguerra española, por el concurso del Estado. La HOAC vallisoletana surge, pues, en este clima de nacionalcatolicismo que inunda toda la AC espaniola. Auspiciada, como en la mayor parte de las diócesis, por el Consejo Diocesano de los Hombres de Acción Católica, en el seno del mismo se constituirá el pertiniente Secretariado Obrero con su Vocal correspondiente. De ahí se pasará a constituir el Grupo Ferroviario, primer esbozo de la obra'. Y aunque a veces dicho grupo recibe el nombre de Comisión Diocesana de $\mathrm{HOAC}^{10}$, lo cierto es que ésta no se establece formalmente hasta 1952, muy ligada, por otro lado, al Consejo diocesano de los Hombres ${ }^{11}$. El núcleo de la Hermandad lo constituyen

\footnotetext{
${ }^{8}$ B. López García, Dilemas..., pp. 15-16.

${ }^{9}$ El primer antecedente es el Centro Ferroviario de RENFE, creado en 1943 con 150 obreros que se reúnen mensualmente. En marzo de 1944 el primer Vocal Obrero del Consejo Diocesano de los Hombres de AC es Rogelio Vázquez, y en 1947 Santiago Quintero; en diciembre de este mismo affo se adhiere a la AC el Grupo Ferroviario, y en enero de 1946 se decide poner en marcha la especialización con el concurso de JOC, Padres de Familia, Hermandad Ferroviaria, Hermandad de San Cosme y San Damián, Círculo Católico de Obreros y Propagandistas: Acción Católica de Valladolid (documentación sin catalogar ni ordenar, en adelante ACdV), Libro de Actas del Consejo Diocesano de Hombres de Acción Catolica de Valladolid, 9-II-1941 a 11-X-1954, Actas núms. 14, 19, 21, 24, 30, pp. 12, 14-15, 18-19.

A la I Semana Nacional de la HOAC (1946) asisten por Valladolid, Jesús Gabriel Rodríguez, Amado Orive, Mario Alvaro Martín (Socios del Grupo Ferroviario vallisoletano), y Serapio Prieto Cantero (Socio del Centro de San Lorenzo): id., «Acta del Consejo Diocesano, n. ${ }^{\circ} 36,14$ de octubre de 1946m, p. 22.

${ }_{10}$ El primer presidente de esta CD oficiosa es Santiago Quintero, y como Consiliario está el Viceconsiliario de los Hombres de AC, José Rodriguez. Incluso Marcelo González, futuro primado de España y alora Consiliario de este Consejo Diocesano, planea crear la HOAC vallisoletana integrándola en la JOC: Ibid., Libro de Actas del Consejo Diocesano de Hombres de Acción Católica: del 9 de febrero de 1941 al 11 de octubre de 1954, «Acta del Consejo Diocesano n. ${ }^{\circ} 44,15$ de junio de 1948«, p. 29.

11 Para constituir oficialmente la HOAC de Valladolid, Marcelo González contacta con el sacerdote José María Arévalo y con el ferroviario Amado Orive, que por entonces era presidente de la Juventud
}

Actas del I Congreso de Historia de la Iglesia y el Mundo Hispánico

Hispania Sacra, 52 (2000) 
unos cuantos ferroviarios de RENFE y algunos antiguos jocistas que, intimamente ligados a la AC general y auspiciados por la Hermandad Ferroviaria y demás asociaciones adultas, iniciarán la andadura de esta «primera» $\mathrm{HOAC}^{12}$.

Ésta se mueve dentro del estilo tradicional de la $\mathrm{AC}$ espaffola de posguerra, es decir, potenciando la vida de piedad como medio idóneo para lograr la recristianización del mundo obrero ${ }^{13}$; habrá que esperar hasta finales de los cincuenta para poder hablar de encarnación en la clase obrera. Mientras tanto, la HOAC de Valladolid, escasamente consolidada, centraba todos sus esfuerzos en poner en marcha los instrumentos formativos y consolidar la obra mediante la captación de obreros. A este respecto, los inicios son bastante duros, pues el número de militantes es reducido, el Consiliario no parece responder a las expectativas de este apostolado, y la presencia en la ciudad de la Sección de Antiguos Jocistas, relativamente numerosa y vinculada afectivamente a la JOC de los afios republicanos, restaba militancia a la Hermandad. A pesar de ello, con el paso del tiempo la Sección se convertirá en el filón que impulse la HOAC, pues, vista la precariedad organizativa y el escaso peso social de la organización, los hoacistas se esforzarán -y lograrán- fundir en la Hermandad ambas organizaciones. En efecto, tras cinco años de duras negociaciones con el arzobispo y con el consiliario de la Sección ${ }^{14}$, en noviembre de 1963 se oficializa la fusión de ambos movimientos, si bien la Sección, debido a las presiones de antiguos jocistas, continuará existiendo con aquellos que libremente optasen por mentenerla viva ${ }^{15}$. Lo cierto es que la mayoría pasó a la HOAC, la cual vio incrementar, gracias a esta fusión, la calidad y cantidad de sus efectivos militantes ${ }^{16}$.

de Acción Católica del Barrio de San Andrés: Hombres de Acción Católica. Historia de trece años, 194]-1954, Ed. Sever-Cuesta, Valladolid, 1954, pág. 10; ACdV, Carpeta HOAC, «Acta de Constitución»; Archivo de la Curia de Valladolid (en adelante ACV), Caja «Acción Católica, 1939-1948», carta del Consiliario diocesano de los Hombres de AC al arzobispo de Valladolid, 11 de diciembre de 1951.

12 Esta era la composición: Presidente: Amado Orive Yuste, obrero de RENFE; Consiliario: José María Arévalo; Vicepresidente: Pedro Diaz Ramos, oficial de Imprenta; Tesorero: Leoncio Tamariz Parrado, mozo de almacén de RENFE; Secretario: Florentino Gil Alvarez, ferroviario; Vocal de Piedad: Alejandro Fernández Tejedo, mozo de almacén de RENFE; Vocal de Conquista: Leonardo Vaquero Velasco y Vocal de Prensa y Propaganda: Máximo Herrero Olmos, ordenanza de RENFE.

${ }^{13}$ El objetivo era uel acercamiento de hombres a Cristo, y la salvación de las almas propias y de todos los Obreros, poniéndose a disposición de todos», asi como «atraer obreros a nosotros, que es traerlos a Cristo, esto es, al Apostolado Obrerow: Ibid. Carpeta HOAC, «Acta de Constitucións.

${ }^{14}$ Los hoacistas, por ejemplo, acusaban al Consiliario de la Sección, Modesto Herrero, de planear una absorción de la HOAC por parte de los Antiguos Jocistas: Archivo de la Comisión Nacional de la HOAC (en adelante ACNHOAC), Caja 92, carpeta 5, Carta a la CN, 15 de noviembre de 1961.

is ACNHOAC, Caja 130, carpeta 4: Carta a la CN, 10 de noviembre de 1963; ACV, Caja Movimientos de AC-Aposfolado Seglar, Carpeta «AC-Juventud Obera Catolica. Valladolid», Decreto del arzobispo, Valladolid, 23 de septiembre de 1963.

16 Pasaron a ser casi 120, y el nuevo presidente de HOAC fue el antiguo jocista Ricardo San José. 
Pese a los problemas inevitables de dicha incorporación (diferente mentalidad, dificultad para asimilar el Plan Cíclico, exigencias del compromiso, etc.) este hecho supuso el despegue definitivo de la HOAC de Valladolid. A partir de ahora se puede hablar de su segunda etapa, caracterizada principalmente por el incremento del peso eclesial y el auge del compromiso temporal. La combinación entre el espíritu obrerista, la encarnación en la clase obrera y el contexto político, social y sindical del país, explica que el compromiso militante de los hoacistas vallisoletanos adquiera resonancias espectaculares. Se trataba de crear líderes obreros, de evangelizar a los trabajadores elevando su grado de conciencia, facilitando su promoción integral, actuando como levadura en medio de la masa obrera e intentando aproximar dos realidades que hasta entonces parecian irreconciliables: Iglesia y mundo obrero. Era una HOAC que, en estos primeros tiempos, se concebía como vanguardia de la clase obrera y actuaba como tal: pocos militantes pero activos, formados y dinámicos que, con su testimonio personal en los lugares de trabajo y su defensa sincera de los intereses de los más humildes, procuraban llevar a cabo, con toda la eficacia posible, su labor apostólica. El protagonista era el obrero concreto con sus problemas concretos, al que había que atraerse ya no sólo con actividades de tipo caritativo y espiritual, sino también, y prioritariamente, mediante la elevación de su grado de conciencia y la promoción integral del mismo.

Todo esto vino refrendado e impulsado, desde mediados de los sesenta, por la renovación conciliar. Es cierto que el Vaticano II fue vivido por los militantes hoacistas como el refrendo de una actitud apostólica que ellos venían practicando desde años atrás, pero también lo es que radicalizó sus propuestas e impulsó más decididamente su compromiso social y político. El desfase entre unos movimientos apostólicos comprometidos seriamente con la realidad obrera y una jerarquía eclesiástica que, poco a poco, con vacilaciones y resistencias, trataba de asumir esos nuevos postulados, se hizo progresivamente más problemático. Si a esto sumamos el contexto político espafiol, los crecientes problemas -represión política, crisis de identidad, problemas de fe- en el seno de la HOAC, y la actitud poco acertada de la jerarquía eclesiástica, podremos comprender la gran crisis desatada desde finales de los años sesenta en el seno de la HOAC y demás movimientos especializados.

En efecto, desde el affaire de 1965-1967, la HOAC de Valladolid, como organización apostólica, caerá en picado ${ }^{17}$. La salida de militantes, la división HOAC-ZYX, la desesperanza y la desmotivación de los pocos que quedaron, hicieron que fuese prácticamente imposible su recuperación. Entre 1970 y 1975

${ }^{17}$ Los ejemplos y las citas se podrían multiplicar. Ver por ejemplo ACNHOAC, Caja 69, carpeta 5 : Acta del Pleno Nacional de Presidentes, Majadahonda, 30-31 de enero de 1971.

Actas del I Congreso de Historia de la Iglesia y el Mundo Hispánico

Hispania Sacra, 52 (2000) 
se multiplican los intentos por reflotar la obra, y aunque ya nada era como antes y la debilidad era manifiesta, quedará un leve rescoldo que, con mucho esfuerzo, intentará que la HOAC de Valladolid recobre vida.

Pese a todo, la organización podría decaer pero no la actividad individual de los militantes. En efecto, en los años setenta, el auge del movimiento obrero en Valladolid será posible, ehtre otras cosas, gracias al concurso de hoacistas, socialistas, comunistas y otros militantes cristianos, en especial de la JOC. Ahora, la misión apostólica de la HOAC asumía la novedad eclesial y teológica de lo que se ha denominado Iglesia Popular o Iglesia paralela, enfatizaba el carácter comunitario de la obra y afirmaba el talante revolucionario de la acción evangelizadora. El diálogo con el marxismo, la creencia firme en la autogestión, y la afirmación del compromiso político-social como condición imprescindible para construir el Reino de Dios, fueron circunstancias que posibilitaron el que los hoacistas siguiesen empeffados en la promoción integral de la clase obrera mediante la transformación radical de las estructuras. Como enseguida veremos, todo esto adquirirá una concreción y unas consecuencias bastante destacadas.

\section{LOS MIITTANTES HOACISTAS EN EL RESURGIMIENTO DEL MOVIMIENTO OBRERO EN VALLADOLID}

Como hemos dicho, los hoacistas vallisoletanos no tendrán una participación destacada en el terreno político-sindical hasta mediados de los años sesenta. Una vez establecida la fusión con los Antiguos Jocistas e impulsado el compromiso temporal, las actividades en este sentido serán bastante destacadas. Se centrarán, fundamentalmente, en la participación como enlaces y vocales jurados en diversos conflictos y reivindicaciones laborales, en escritos y celebraciones con claro matiz político, y en la puesta en funcionamiento de organizaciones o plataformas sindicales como CCOO y USO, así como el movimiento asambleario y vecinal. Además, desde principios de la década de los sesenta, los hoacistas conectarán, a nivel individual, con otros militantes comprometidos en la oposición al Régimen ${ }^{18}$.

\footnotetext{
${ }^{18}$ Como seffiala Ricardo San José, entre 1963 y 1964 los militantes de la HOAC participan en «Plataformas de acción social», reunidas en la Casa-lglesia de la Pilarica y apoyadas por los jesuitas. También en los locales de los dominicos; a ellas acudían personas de diferentes ideologías (comunistas, socialistas, cristianos...) y personalidades que luego tendrán importantes cargos políticos en partidos de izquierda: 50 Aniversario de la HOAC. VII Encuentro Interdiocesano sobre el compromiso de la HOAC en Castilla y León, Valladolid, 23 de abril de 1996; entrevista con Ricardo San José, 10 de marzo de
} 1998. 
En este sentido, junto a la labor de apostolado propia de la Hermandad, nos encontramos con toda una serie de factores que facilitan y explican esta labor: los instrumentos legales aportados por el Régimen con el fin de incrementar la representatividad y la participación de los obreros en el entramado sindical y laboral (elecciones, Jurados, Ley de Convenios Colectivos...), las transformaciones económicas y sociales aceleradas desde mediados de los sesenta (desarrollo económico e industrial de Valladolid, aportación de nuevas generaciones al movimiento obrero...), la renovación eclesial, la irrupción con fuerza de la contestación clerical, la aparición y el fomento de Comunidades de base -fines de los sesenta-, la activación de los movimientos de oposición entre la juventud universitaria, y la actividad de democristianos, socialistas, comunistas y demás militantes comprometidos en la oposición al Régimen.

\section{a) Como enlaces y vocales jurados}

A mediados de los cincuenta, la HOAC de Valladolid, carente de solidez formativa, decía no encontrarse preparada para lanzar a sus militantes al compromiso sindical ${ }^{19}$. A comienzaos de la década posterior, $\mathrm{y}$ aunque a ojos de la organización la actividad del Jurado aparecía inútil e ineficaz ${ }^{20}$, destacados militantes se sumaron a la táctica del copo en las elecciones sindicales y resultaron elegidos junto a otros de procedencia jocista e independiente. En 1962, y a partir del núcleo de RENFE, se hicieron con el control del sindicato de Transportes, y cuatro atfos más tarde, esta vez como trabajores de FASA, copaban el del $\mathrm{Metal}^{21}$. Las autoridades comenzaron a ver con malos ojos esta labor, y mucho más cuando dichos militantes no sólo lideraban las protestas contra determinadas situaciones laborales, sino que incluso elevaban escritos en contra del sistema sindical vigente ${ }^{22}$. Y es que, a mediados de la década, hoacistas y jocistas solicitaban la implantación de un sindicato libre, verdaderamente repre-

19 ACNHOAC, Caja 69b, carpeta 8: Acta de la Reunión Trimestral de Zona, Valladolid, 5 de febrero de 1956.

20 Ibidem.

21 Entre los más combativos de la HOAC estaban Benedicto Garcia Tajadura, Antonio Ruipérez, A. Madrigal (trabajador de FASA procedente de Palencia) y Valeriano Benito Morillo: Entrevista con Pedro Oyagliez Valentin y con Antonio Rujpérez, Valladolid, 2 de junio de 1998; id. con Valeriano Benito, Valladolid, 19 de abril de 1999.

22 Por ejemplo, en 1964 presentaron una ponencia en el Congreso Sindical en la que denunciaban el sistema sindical espaniol y pedían la libertad y la autonomia sindical, la libre elección y revocación de los representantes. Esto les generó un importante conflicto con el Delegado Sindical y motivó un duro debate con el Asesor Eclesiástico, Eduardo Sánchez, como testigo y mediador: documento fechado el 28 de febrero de 1964 y cedido al autor por Valeriano Benito.

Actas del I Congreso de Historia de la Iglesia y el Mundo Hispánico Hispania Sacra, 52 (2000) 
sentativo y eficaz, exclusivamente obrero y autónomo; lo más importante es que empleaban para ello documentos conciliares ${ }^{23}$.

Para estos hoacistas, la evangelización del mundo obrero requería inexcusablemente la promoción integral y colectiva de la clase trabajadora, lo cual conllevaba consecuencias de índole social, política y sindical: a su juicio, dicha promoción sólo era posible en un sistema democrático y de plena libertad sindical, por lo que su objetivo más inmediato era entrar en el sindicato y acabar con él desde dentro ${ }^{24}$.

Tras la crisis de la Acción Católica, y más aún a inicios de la década posterior, se replantea el compromiso sindical. Algunos militantes continúan desempefiando cargos sindicales, pero el descrédito del sistema y la apuesta decidida por el movimiento asambleario provocan el abandono de la representación oficial y la asunción de otra estrategia ${ }^{25}$. Ya no se trata de acabar con el sindicato desde dentro sino de sustituir los cargos sindicales por las comisiones elegidas en las asambleas, convertidas éstas en órganos verdaderamente representativos de los intereses obreros.

\section{b) Escritos y denuncias}

A medida que avanzaban en el compromiso, los hoacistas de Valladolid se fueron convenciendo de que el sistema de relaciones laborales y el régimen político vigente en España constituían uno de los principales escollos para avanzar en la evangelización y promoción integral de la clase obrera. De esta mane$\mathrm{ra}$, a principios de los años sesenta, los GOES, basándose en postulados de la Doctrina Social de la Iglesia, achacaban al Régimen político y sindical buena

${ }^{23}$ A principios de 1967, el hoacista Benedicto García Tajadura criticaba en la Reunión de la Sección Social de RENFE la exigua subida salarial y ponía de manifiesto la inutilidad del sindicato vertical y la urgencia de la libertad de asociación: Archivo Histórico Provincial de Valladolid (en adelante AHPV), Sección AISS, Caja 4977. Y en el escrito publicado en Diario Regional en 1968, la representación sindical de esta misma empresa refrenda esas quejas con la Mater et Magistra y la Pacem in Terris: id. Por otro lado, el 23 de julio de este mismo affo, la Sección Social del Jurado de Empresa de FASA, donde figuraban numerosos militantes de HOAC y JOC, escriben una carta en solidaridad con 11 despedidos de la factoria sevillana (id.) Un año antes habia salido a la luz un escrito contra el sindicalismo español ante la futura Ley Sindical, y entre los firmantes estaban e1 hoacista Valeriano Benito Morillo (subjefe del Grupo Social de RENFE) y el también hoacista García Tajadura, como Vicepresidente de la Sección Social de Transportes (el Presidente es Melchor San José, y el jefe del Grupo Social de RENFE era Mario Blanco del Barrio): en este escrito, publicado en Diario Regional con fecha de 4 de noviembre de 1967, se alude a la Gaudium el Spes, a la Pacem in Terris, a la Declaración Universal de los Derechos Hurnanos y a los escritos de la OIT: id.

${ }^{24}$ Entrevista con Pedro Oyaglez Valentín y con Antonio Ruipérez, Valladolid, 2 de junio de 1998.

${ }^{25}$ Ibidem. 
parte de la injusticia reinante en el pais ${ }^{26}$. Muy influidos por el contexto nacional y europeo, en los años setenta, los hoacistas de Valladolid proponían la instauración de un socialismo autogestionario como medio más eficaz para satisfacer las exigencias evangélicas de fraternidad y justicia. Evidentemente, esto radicalizó aún más su mensaje y actitud. Como vemos, el auge del izquierdismo y la politización del movimiento obrero español no pasaron desapercibidos a los movimientos apostólicos.

Esto les dio pie para elaborar escritos fuertemente reivindicativos y dirigirlos a la jerarquía eclesiástica, a las autoridades civiles y a la opinión pública en general. La mayoría de ellos insisten en el desprestigio del sindicato vertical, al que consideran ineficaz y opresor de la clase obrera, propugnan un sindicato libre, democrático, autónomo y verdaderamente representativo, denuncian el sistema económico y político imperante en España, y reclaman libertades democráticas y un sistema social y económico más justo, cuando no socialista. Escritos contra el estado de excepción, contra La Ley Sindical -algunos difundidos en mano por los militantes en sus propias empresas-, contra la suspensión del artículo 18 del Fuero de los Españoles, en solidaridad con las huelgas de FASA y de la Construcción, etc., evidencian esta postura ${ }^{27}$. Evidentemente algunos de ellos sufrieron multas y sanciones gubernativas.

Junto a los escritos, la HOAC intensifić el carácter reivindicativo de las celebraciones del $1 .^{\circ}$ de mayo. En Valladolid, como en el resto de Espaffa, la de 1960 fue el principio de todo un rosario de vigilancia y persecuciones por parte

26 Los GOES eran grupitos de 3 a 6 obreros, militantes y simpatizantes de la HOAC, que estudiaban, según la metodología de encuesta, temas de índole sindical, económica y cívico-política. Un ejemplo de esto que decimos en ACNHOAC, Caja 75, carpetas 3, 4 y 5, GOES «9-A», y «33-A», Cuarto Trabajo, noviembre de 1963-febrero de 1964.

27 Sobre el estado de excepción de 1969, firmado por HOAC, VOJ, VOS, MAS, ME, JOC, JOCF y ZYX (en J. DOMinGUEZ, La lucha obrera durante el franquismo en sus documentos (1939-1975), Bilbao, Desclée de Brouwer, 1977, pp. 347-349).

Contra la Ley Sindical tenemos el firmado en octubre de 1969 por HOAC, JOC, VOJ, VOS y MAS (Archivo de CURIA (ACV), Carpeta «Obrero», 27 de octubre de 1969); y a título personal el del hoacista A. Ruipx́rez en Garteiz y Hemanos y los de otros militantes en Belloit y Segura (AHPV, Sección AISS, Caja 4991, Carta de Hernando Estrada a A. Chozas, 8 de noviembre de 1968, e id., "Informe confidencials, 9 de noviembre de 1968).

Sobre el sistema político y los conflictos obreros, son de destacar: las «Reflexiones en torno al $1 .^{\circ}$ de mayo" (1970), aparecidas en El Norte de Castilla y enviadas al arzobispo (ACV, Carpeta «Obrero"), el escrito del 1 de mayo de 1971 contra la suspensión del artículo 18 del Fuero de los Españoles (ACNHOAC, Caja 249, carpeta 1, Valladolid, 1 de mayo de 1971), las «Reflexiones cristianas ante el conflicto laboral de la construcción en Valladolid), del 11 de noviembre de 1973 (ibid., Caja 320, carpeta 4, también en Archivo Regional de Comisiones Obreras de Castilla y León -en adelante: ARCCOOCL-, Caja 63, carpeta 1), y la hoja Al pueblo de Valladolid (octubre de 1974), por los sucesos de FASA (ibid, carpeta 2 ).

Actas del I Congreso de Historia de la Iglesia y el Mundo Hispánico

Hispania Sacra, 52 (2000) 
de la autoridad gubernativa ${ }^{28}$. Y ello debido a la difusión de un Llamamiento que exigía mayores cuotas de justicia social y al carácter fuertemente obrerista de las conferencias. Y en 1968 , el mensaje del $10^{\circ}$ de mayo celebrado por los movimientos apostólicos en la iglesia de San Pablo, donde estaban reunidos muchos activistas de la oposición, esgrimió documentos conciliares para arremeter duramente contra el sistema político español ${ }^{29}$. Por fin, al año siguiente, en pleno estado de excepción, la celebración vino acompañada de la difusión de hojas clandestinas firmadas por CC.OO. ${ }^{30}$. Como vemos, a estas alturas, el $1 .^{\circ}$ de mayo celebrado por los Movimientos Apostólicos se había convertido en una plataforma privilegiada para todos aquellos colectivos interesados en la lucha por la democracia.

c) La promoción de nuevas plataformas sindicales y el movimiento asambleario

Una vez comprobada la ineficacia del sindicato vertical, los hoacistas de Valladolid procedieron a impulsar, junto a comunistas, militantes cristianos y obreros independientes, nuevas plataformas sindicales o asociativas. Como es bien sabido, la unión para resolver conflictos laborales y el protagonismo otorgado a la base obrera impulsaron el carácter espontáneo de las primeras comisiones obreras, mientras las tendencias autogestionarias alimentaban la creación y puesta en marcha de USO, sindicato impulsado, principalmente, por JOC.

A principios de los 60 son militantes de HOAC y JOC los que lanzan esta última organización en Valladolid, primero en RENFE y más tarde en FASA ${ }^{31}$.

${ }^{28}$ Cuando iban a ver los actos del $1 .^{\circ}$ de mayo en el Centro Obrero Católico, el Presidente nacional de la HOAC, Teófilo Pérez Rey, y el diocesano de Valladolid, Amado Orive, fueron abordados por la policía y conducidos a comisaria; lo mismo hicieron con varios miembros del Centro Obrero Católico para incautarse de los paquetes que había llevado allí el Vocal Nacional Luis Altable y que contenían el citado Llamamiento. El Comisario Jefe advirtió a Pérez Rey «que tuviera cuidado con sus actuaciones en aquella ciudadr: ACNHOAC, Caja 201, carpeta 4: informe sobre los sucesoso del $10^{\circ}$ de mayo de 1960 en Valladolid.

${ }^{29}$ AHPV, Sección AISS, Caja 2761, Informes de la Vicesecretaría Provincial de Ordenación Social, 15 de octubre de 1968; AHPV, ibid, caja 4977 (Delegado y Secretaría Particular. Ciudad, 1967-1968), nota al Gobernador Civil, 4-IX-1968; ibid., informe reservado de 25-X-1968; Archivo General de la Administración (en adelante AGA), Sección Ministerio de Cultura-Gabinete de Enlace, Caja 569, Informe confidencial de la Dirección General de Seguridad-Brigada de Investigación Social, 13 de mayo de 1968.

30 AGA, Sección M. de Cultura-Gabinete de Enlace, Caja 564, Información de la Comisaría General de Investigación Social, julio de 1975.

${ }^{31}$ EI núcleo fue RENFE y de la HOAC estaban Valeriano Benito y Benedicto García, y de la JOC Pedro Oyagíez, Carlos Marino Asensio y Mario Blanco. Luego en FASA se incorporaron, por parte de 
Entre sus promotores destacarán, por parte de la HOAC, Valeriano Benito y Benedicto García, y de la JOC, Pedro Oyagüez. Tras la escisión de USO, algunos militantes creyeron traicionada la tendencia autogestionaria y pasaron a formar la plataforma neotrostkista Lucha Obrera, donde estaban Oyagüez, Antonio Ruipérez y otros, con su propia revista ${ }^{32}$.

Por otro lado, la creación de Comisiones Obreras tiene lugar a partir de las reuniones que militantes de HOAC, JOC, VO, militantes comunistas y otros obreros independientes mantienen en la iglesia de San Pablo en torno al año 1968. CCOO surgen en Valladolid desprovistas del carácter espontáneo característico de sus orígenes en otras regiones (mediados/finales de los cincuenta), y son impulsadas, fundamentalmente, por el Partido Comunista. Esto fue motivo de tensiones en su seno, y los militantes hoacistas y jocistas no se sintieron excesivamente identificados con ellas. A pesar de todo, Antonio Ruipérez, Agapito Urueña, Benedicto García y su hermano Félix, todos ellos de la HOAC, participaron en sus primeras reuniones.

No menos importante fue el movimiento asambleario, nacido con fuerza a partir de 1972, al calor de los conflictos de FASA. Alimentado y potenciado por hoacistas y jocistas, este movimiento respondía al ideal de promoción del pueblo por el propio pueblo, quería incentivar la democracia de base, convertirse en la plataforma unitaria de todos los trabajadores concienciados, y remarcar el carácter integral de la lucha obrera ${ }^{33}$. En este sentido, las Asambleas y los Consejos Obreros fueron piezas fundamentales en los conflictos de FASA y Construcción, y si en las primeras fueron hoacistas y jocistas sus principales impulsores, en las segundas lo fueron, casi exclusivamente, militantes de JOC. Además de $\mathrm{CCOO}$, al movimiento asambleario vinieron a unirse la UGT y el PSOE. Su estrategja consistió en sustituir la representación sindical oficial por las comisiones representativas (o plataformas reivindicativas) elegidas por las asambleas, procurando la dimisión de los cargos sindicales -los de HOAC y JOC lo hicieron totalmente- y la negociación directa con la empresa ${ }^{34}$.

la HOAC, Antonio Ruipérez y Juan A. Cañada: Entrevistas citadas con Valeriano Benito, Pedro Oyagüez Valentín y Antonio Ruipérez.

32 Valladolid en Lucha, revista encabezada por Pedro Oyagiez, escrita en colaboración con su hermano Femando y el hoacista Antonio Ruipérez entre otros: entrevista con Pedro Oyagitez Valentín, Valladolid, 26 de mayo de 1998.

33 Junto a Oyagilez y Ruipérez, en el movimiento asambleario estuvieron Juan A. Cafiada, presidente diocesano de la HOAC de Valladolid en 1975, y el también militante Agapito Uruefia.

34 A este respecto, pueden consultarse los centenares de hojas, octavillas y panfletos propagandísticos elaborados por los numerosos grupos de oposición (CC.OO. de FASA, CC.OO. de la Construcción, Plataformas Capitalistas, etc.), en AHPV, Sección AISS, Caja 5645; el propio Delegado Provincial de Sindicatos lo explica en id., Caja 5641, Informes reservados de junio-diciembre de 1974, y 4 de febrero de 1975 . 
d) En el movimiento vecinal: Asambleas Familiares, de Barrio y de Vecinos

Al mismo tiempo que se potenciaban las asambleas como instrumento organizativo primordial del movimiento obrero, los militantes de la HOAC trataron de incrementar el asociacionismo cívico mediante la promoción de asambleas de vecinos. De nuevo se trataba de plasmar la autogestión y la participación del pueblo en la vida municipal ${ }^{35}$. Las carencias de los barrios de la ciudad eran flagrantes, y los hoacistas entendían que sólo el pueblo podía y debía lograr el mejoramiento de sus condiciones de vida por medio de instrumentos que aseguraran la democracia de base. Otra vez entraban en juego los mismos actores: militantes de HOAC y JOC como impulsores, las parroquias como cobijo, y el concurso de vecinos y militantes de otras procedencias ${ }^{36}$. Así, a principios de la década de los setenta nacen las más importantes Asociaciones de Vecinos de los barrios de la ciudad: la Asociación Familiar de La Rondilla, la Asociación del Barrio Belén, la de La Victoria, la de Deliçias y la de Pajarillos. En ellas destacaron militantes de la HOAC como Antonio Ruipérez (Rondilla), Juan A. Cañada y Agapito Urueña (Delicias).

Estas Asociaciones reclamarán derechos elementales como escuelas, viviendas dignas, alumbrado y zonas verdes, fomentarán la conciencia asociativa de los militantes y mostrarán, junto a otras coordinadoras, su solidaridad con las revueltas estudiantiles y con los obreros en huelga de FASA y de la Construcción $^{37}$. Y además de arremeter contra el Régimen vigente, las Asociaciones propugnarán la instauración de la democracia a todos los niveles ${ }^{38}$.

35 Respecto a la acción en los barrios, los hocistas informaban en 1971 que su pretensión era incrementar la colaboración y la acción con los demás grupos obreros mediante la actuación individual de los militantes -en barrios y demás ambientes-, no como organización; de ahi que no exista una planificación de introducción en ambientes. En 1975 la acción municipal de los hoacistas se centraba en los barrios más pobres de Valladolid: ACNHOAC, Caja 249, carpeta 1: Acta de la Reunión de militantes, Valladolid, 18 de enero de 1971; ibid., Caja 79, carpeta 9, Cuestionario de análisis de la situación de Valladolid.

${ }^{36}$ Las parroquias más importantes y comprometidas con el Movimiento Obrero eran La Pilarica, Dulce Nombre de María, Santo Toribio, La Victoria, y Nuestra Sefiora del Camen. Sacerdotes como Buenaventura Alonso Gómez, Gonzalo González Alvarez, Paciano Martínez, Millán Santos o Carmelo Pozas, éste a punto de ordenarse jesuita, fueron conducidos, en más de una ocasión, a las dependencias policiales: ver por ejemplo AHPV, Caja 5641, informes reservados de 14 de diciembre de 1974.

${ }^{37}$ Como el de mayo de 1975, publicado el El Norte de Castilla y en el Boletin HOAC, firmado por la Asociación Faniliar del barrio de las Delicias, la Asociación de Amas de Casa, la de Cabezas Familiares del Barrio de Belén y de la Rondilla, y la Familiar del Barrio de la Victoria: Boletín HOAC, . $^{\circ}$ 664 (mayo de 1975), p. 20.

38 Así lo hacia en 1974 otro escrito elaborado por las Asociaciones Familiares de los Barrios de las Delicias, Belén, La Victoria y la Rondilla, y la Asociación de Amas de Casa de Valladolid: Boletín HOAC, $\mathrm{n}^{\circ}$ 654-A (diciembre de 1974), p. 5. 


\section{VALORACIÓN DE LA ACTIVIDAD DE LA HOAC POR PARTE DE LAS AUTORIDADES VALLISOLETANAS}

De los informes del Gobernador Civil y del Delegado Provincial de Sindicatos se puede colegir que la HOAC y demás movimientos apostólicos -en especial JOC-, fueron objeto preferente de vigilancia. En los años sesenta, la represión a la que se había sometido al resto de las organizaciones obreras aseguraba el papel de suplencia de la Iglesia y sus movimientos especializados, aspecto que las autoridades tenian siempre en cuenta. La formación dispensada por los GOES, por ejemplo, donde participaron gente ajena a la militancia hoacista, atestigua dicha labor. Pero los militantes de la HOAC fueron siempre objeto de vigilancia y represión, sobre todo desde aquel mayo de $1960^{39}$. De esta forma, en medio de un ambiente aparentemente tranquilo, sólo la HOAC, en los primeros affos sesenta, aparecía como la principal amenaza, según las autoridades, para el mantenimiento del orden público y la legitimación del sistema político y sindical vigente ${ }^{40}$. Por ello la acusaban de ser nido de infiltrados comunistas, de propagar ideas marxistas y de intentar acabar con el sindicato y la democracia orgánica española. Como organización no podía ser reprimida, pero los militantes, a título individual, sufrieron detenciones, multas y despidos. En la década de los setenta, las autoridades destacan de nuevo la actividad desplegada por los Movimientos Apostólicos -ahora se refieren sobre todo a $H O A C-J O C$-, los cuales, junto al PC, parroquias obreras, sacerdotes contestatarios, grupos universitarios y abogados jóvenes de filiación democristiana ${ }^{41}$ encabezan estas

${ }^{39}$ En este sentido, los informes son numerosos. Hay referencias personales por parte del Delegado Provincial de Sindicatos respecto a determinados militantes de JOC y HOAC: Pedro Oyagüez, García Tajadura, Antonio Ruipérez, A. Madrigal, Alfonso Maroto, Valeriano Benito Morillo, etc. También encontramos referencias a la HOAC y a la JOC como organizaciones opuestas al régimen político y sindical. Ver por ejemplo: AHPV, Sección AISS, Caja 5642, Informes al Gobernador Civil, 21 de enero de 1974; Caja 5641, Informe reservado de 14 de octubre de 1974; Caja 5645, carta del Delegado Provincial de Sindicatos al Director del Servicio de Información y Publicaciones Sindicales, 8 de marzo de 1974, e informes internos de junio de 1974, 16 de diciembre de 1974 y 4 de febrero de 1975 .

40 En 1964, el Gobernador Civil informaba de que si bien no se habian producido en la ciudad altercados graves, «los únicos focos de descontento procedieron de las organizaciones de signo cristiano, JOC y HOAC, especialmente esta última que se muestra partidaria de procedimientos avanzados coincidentes con los preconizados por la extrema izquierda: el derecho a la huelga y los sindicatos libres». Sobre su influencia antisindical, seffalaba que era «más de principios que de gestión», y que atacaba la unidad, la verticalidad, el encuadramiento y la línea política de la OSE; y todo esto prendía, según el Gobernador, entre «la población de aprendizaje y los núcleos ferroviarios de la Capital y Medina del Campon: AGA, Caja 11697, Memorias del Gobiemo Civil, 1964.

41 Entre las parroquias destacan, sobre todo, la Pilarica y Santo Toribio. Muy importante fue la Librería Villalar, como centro de reunión y debate de la oposición. Y entre los abogados tenemos a Fernández de la Reguera, Terradillos, Alonso Francha, Pérez Solano e Izquierdo: AHPV, Sección AISS, Caja 5641, Informe reservado, 1974, p. 12.

Actas del 1 Congreso de Historia de la Iglesia y el Mundo Hispánico Hispania Sacra, 52 (2000) 
actividades; sin duda, los dos primeros grupos lideran la oposición al régimen. De nuevo se les trata como meras pantallas del Partido Comunista ${ }^{42}$, connotación que indignaba a los militantes hoacistas y que pone en evidencia, por otro lado, el protagonismo de dicho Partido en la oposición al régimen. En efecto, las autoridades veían en todo movimiento de oposición la mano escondida de los comunistas, y también en la acción desempeñada por los militantes de la HOAC. El languidecimiento de la organización apostólica, la desinformación de las autoridades y la labor desinteresada y ajena a todo proselitismo que caracterizaba a los hoacistas, son los principales factores que ayudan a comprender este hecho. Evidentemente, a ello deberemos unir el auge del PC y su afán por monopolizar toda la contestación al Régimen ${ }^{43}$.

${ }^{42}$ «(...) están profundamente infiltrados por el PCE, hasta el punto de obedecer fielmente, en ocasiones, las consignas del mismon: AHPV, Sección AISS, Caja 5641, Informe del Delegado Provincial de Sindicatos, 1974.

43 Junto a las entrevistas ya citadas, hemos podido comprobar esta misma opinión entre los hoacistas de otras zonas castellanas, como León, Soria y Palencia. También otros sacerdotes comprometidos con el movimiento obrero vallisoletano, como Paciano Martínez, por entonces párroco de la iglesia de La Victoria y de San José Obrero, seffalaba este hecho: entrevista con Paciano Martinez, Valladolid, 25 de mayo de 1998.

Actas del I Congreso de Historia de la Iglesia y el Mundo Hispánico Hispania Sacra, 52 (2000) 